\title{
Effect of the National Early Warning Score Education Program on Nurses' Knowledge at an Emergency Hospital
}

\author{
Mohamed Naeem Badr ${ }^{1}$, Nahla Shaaban Khalil ${ }^{2}$, Ahmed Mohamed Mukhtar ${ }^{3}$ \\ ${ }^{1}$ Assistant lecturer of Critical care \& Emergency Nursing, Faculty of Nursing, Cairo University, ${ }^{2}$ Professor of \\ Critical care \& Emergency Nursing, Faculty of Nursing, Cairo University, ${ }^{3}$ Professor of Anesthesia \& Intensive \\ Care Medicine, Faculty of Medicine, Cairo University
}

\begin{abstract}
Aims and Objectives: To determine the effect of a designed program about the National Early Warning Score on nurses' knowledge at an emergency hospital. Background: The Early Warning Score has been developed as a tool for early detection of patients' deterioration. However, its implementation has not been optimal due to the lack of knowledge and understanding of EWS among staff nurses. Design: Pre-test/posttest quasi-experimental research design. Methods: A convenient sample of 34 nursing staff working at the inpatient unit at an emergency hospital was included in the education program. Results: The current findings revealed that all nurses (100\%) (34) had an unsatisfactory knowledge level pre-educational program. While nurses' knowledge level post-educational program showed, most of them (97.1\%) (33) had a satisfactory knowledge level. And there was a highly significant statistical difference between pre-test and post-test of knowledge $(\mathrm{p}<0.001)$. Moreover, nearly half of the nurses $(50.2 \%)$ answered knowledge questions incorrectly pre-educational program, while post-educational program, the majority of them (91.6\%) answered knowledge questions correctly. Conclusion: After implementing an educational program regarding National Early Warning Score, The emergency care nurses' knowledge was markedly improved.
\end{abstract}

Keywords: Early Warning Scores, education, knowledge, nursing.

\section{Introduction}

Patient safety is a prime concern for healthcare professionals. Changes in the patient's physical condition result in hemodynamic instability as the critical bodily functions start to fail ${ }^{[1]}$ and may be detected by observing and recording the patient's physiological vital signs ${ }^{[2]}$ Early detection of deterioration in patients requires accurate and timely documentation of vital signs, interpretation of findings, and acting quickly and appropriately ${ }^{[3-4]}$ which cannot occur without continuous education ${ }^{[5]}$

Corresponding author: Mohamed Naeem Badr

Email :mohamed.badr2002@gmail.com
Early warning systems were developed to improve the assessment and documentation of vital signs in the hospital setting by introducing a unified, standardized concept on a national basis. This concept was called the National Early Warning Score (NEWS) ${ }^{[6]}$. Many hospitals are now using early warning scoring systems as objective methods to identify patient deterioration and ensure timely care. It also provides a standardized observation system and continuity of patient care between wards ${ }^{[7]}$. Which in turn, particular attention can be seen early by a specialized team, reducing the potential risk for adverse events ${ }^{[8]}$.

Nurses are often in frontline positions and are challenged by complex clinical situations requiring skillful application of knowledge for decisionmaking and recognizing signs of patient deterioration. Appropriate action limits serious adverse events (SAEs) 
[9]. One of the key advantages of NEWS is a standardized system for the education, training, and credentialing of healthcare members. So it is recommended that education, training, and demonstrable competency in the use of early warning score should be a mandatory requirement for all healthcare staff engaged in assessing and monitoring acutely ill patients ${ }^{[6,10]}$.

We hypothesized that the post-test mean knowledge assessment scores of emergency care nurses who attend the NEWS educational program would be higher than their mean pre-test knowledge assessment scores.

Design: A quasi-experimental (intervention group) research design was utilized in the current study. It is a type of experimental design that shares with all other experimental designs a similar purpose of testing descriptive causal hypotheses about manipulating causes and many structural details, such as the frequent presence of pre-test measures.

Study setting and sample: This study was conducted at an inpatient unit in an emergency hospital. It provides specialized medical and surgical care to seriously ill patients.

A sample of 34 nursing staff working at the inpatient unit at an emergency hospital and providing direct patient care and are willing to participate in our study was included in the educational program. According to the institutional review board for the protection of human rights, the ethics committee at the faculty of nursing, Cairo University, Egypt, approved the study protocol.

\section{Instruments:}

Instrument 1: Nurses' demographic datasheet: covers data related to age, sex, and educational level.

\section{Instrument 2: Pre / Post-test Knowledge} Assessment Questionnaire: to assess nurses' knowledge related to the national early warning score before and after educational program implementation. It is a self-administered questionnaire; it consists of 15 multiple choice and true/ false questions. The items were categorized under four main domains as follows;
Medico-legal Update, October-December 2021, Vol.21, No. 4261

a. General knowledge about NEWS (questions 1, 2,11 , and 12)

b. Physiological parameters incorporated into the NEWS (questions 3, 5, and 6)

c. How the NEWS work (questions 4, 7, 8, and 13)

d. Using the NEWS (questions 9, 10, 14, and 15)

Scoring system: A total score of 15 grades; each correct answer has got one grade. The total scores are classified as follows; scores of less than 12 out of 15 scores (less than 75\%) are considered unsatisfactory knowledge level, and scores equal to or more than 12 (more than or equal $75 \%$ ) are considered satisfactory knowledge level.

\section{Validity and reliability Instruments}

The developed instruments were examined by a panel of experts in critical care nursing and critical care medicine to determine whether the included items are clear and suitable to achieve the aim of the current study. The developed instrument regarding knowledge questionnaire was tested for reliability utilizing Interrater reliability with Cohen's kappa $=0.85$.

Procedure: it conducted over three phases.

Preparation phase: It was concerned with designing, adopting, constructing the study instruments and designing the nursing educational program, and setting the timetable to deliver the program's contents. The education program about the national early warning score consisted of a lecture through face-toface teaching; the overall training hours were three. The researcher approaches the responsible nursing head nurse of the emergency inpatient unit to specify a training room equipped with a computer and data show to teach the program contents, in addition to obtaining the other managerial agreements to carry out this study.

Implementation phase: Data were collected from September to October 2018. The implementation of the study was started by obtaining a list of involved nurses in the morning, afternoon, and night shifts from 
the monthly schedule. The selected emergency unit was visited, and nurses were approached during their working shifts where the purpose and nature of the study were explained, and written consents were obtained from those who accepted to participate in our study. Then involved nurses were asked to fill out the first and second data collection instruments, nurses' demographic data, and pre-test knowledge assessment questionnaire. The researcher was available to clarify and answer any questions and to provide any needed explanations. The sheet required about 25-30 minutes to be filled by each nurse.

The involved 34 nurses were divided into four groups according to their schedule time. The average number of nurses scheduled to attend the educational program sessions was $8-9$ per session. One group was met daily during the conduction of the program. The program is designed to help understand vital signs' physiological parameters, reasons for measurement and abnormalities, and establish a communication framework between the health care members. It covered the following learning topics; introduction, benefits of NEWS, six physiological parameters included, outline how NEWS works, threshold and triggers, demonstrating correct use of NEWS and its clinical response. The education program's overall duration was around two months to cover all the study samples' training.

Evaluation phase: the researcher followed up and documented the set program's outcomes using the pre-test/post-test knowledge assessment questionnaire (instrument 2) and the nurses' knowledge compared by the investigator before and after implementing the program.

\section{Results}

\section{Nurses' demographic datasheet:}

It is apparent from Fig (1) showed that about twothirds of the studied sample (59\%) were females

Table (1) showed that $35.3 \%$ of the nurses' age was 22 years, with a mean age of $(23.09+1.026)$. As regards educational level, all of the nurses included in the educational program (100\%) (34) have a bachelor's degree, in addition to 11 of 34 (32.3\%) have a technical educational background.

\section{Nurses' knowledge pre \& post educational program}

It is apparent from Fig (2) that the total mean knowledge scores of the nurse's pre-educational program were $(7.44+2.286)$ out of 15 , while the post-educational program was $(13.68+1.121)$. In relation to knowledge sub-items regarding the pre-educational program; the sub-item related to general knowledge about NEWS has got the highest mean scores $(2.7353+.86371)$ out of 4 while the sub item related to using the NEWS has got the lowest mean scores $(1.2059+.84493)$ out of 4 . Posteducational program; the sub-items related to general knowledge about NEWS and how the NEWS work has got the highest same mean scores $(3.7353+.51102)$ out of 4 , while the sub item related to physiological parameters incorporated into the NEWS has got the lowest mean scores $(2.9118+.28790)$ out of 4 .

As can be seen from Table (2), it showed a highly significant statistical correlation between all subtotal knowledge scores in relation to pre \& post educational program.

It is apparent from Figure (3) revealed that all of the nurses (100\%) (34) had got an unsatisfactory knowledge level pre-educational program regarding the national early warning score. While nurses' knowledge level post-educational program showed, most of them (97.1\%) (33) had a satisfactory knowledge level.

As illustrated in Figure (4), nearly half of the nurses $(50.2 \%)$ answered knowledge questions incorrectly preeducational program regarding the national early warning score. While post-educational program, the majority of them $(91.6 \%)$ answered knowledge questions correctly.

It is apparent from Table (3) revealed that there was a highly significant statistical correlation between total pre-knowledge and total post-knowledge score among the studied nurses' sample. 


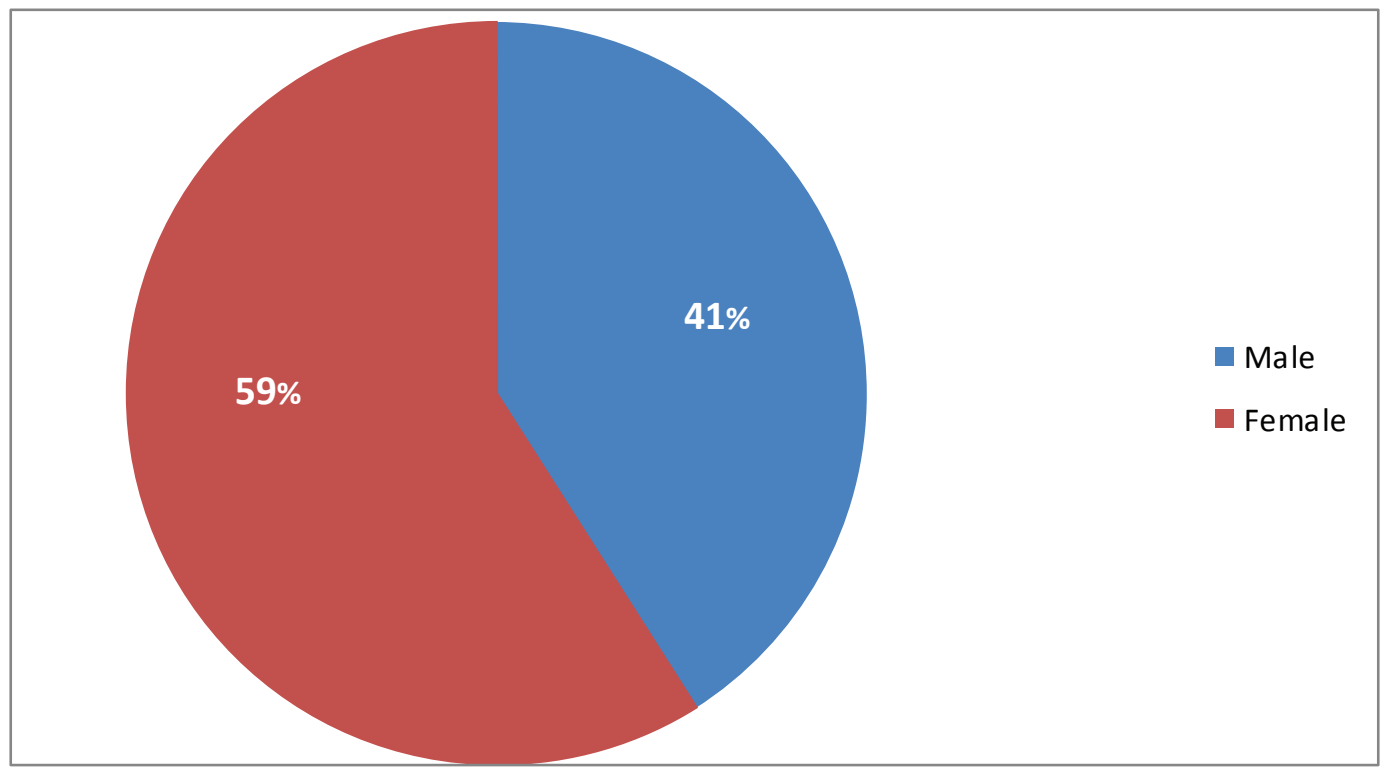

Figure 1: Percentage distribution of the nurses in relation to their gender

Table 1: Percentage distribution of the nurses in relation to their age and educational level

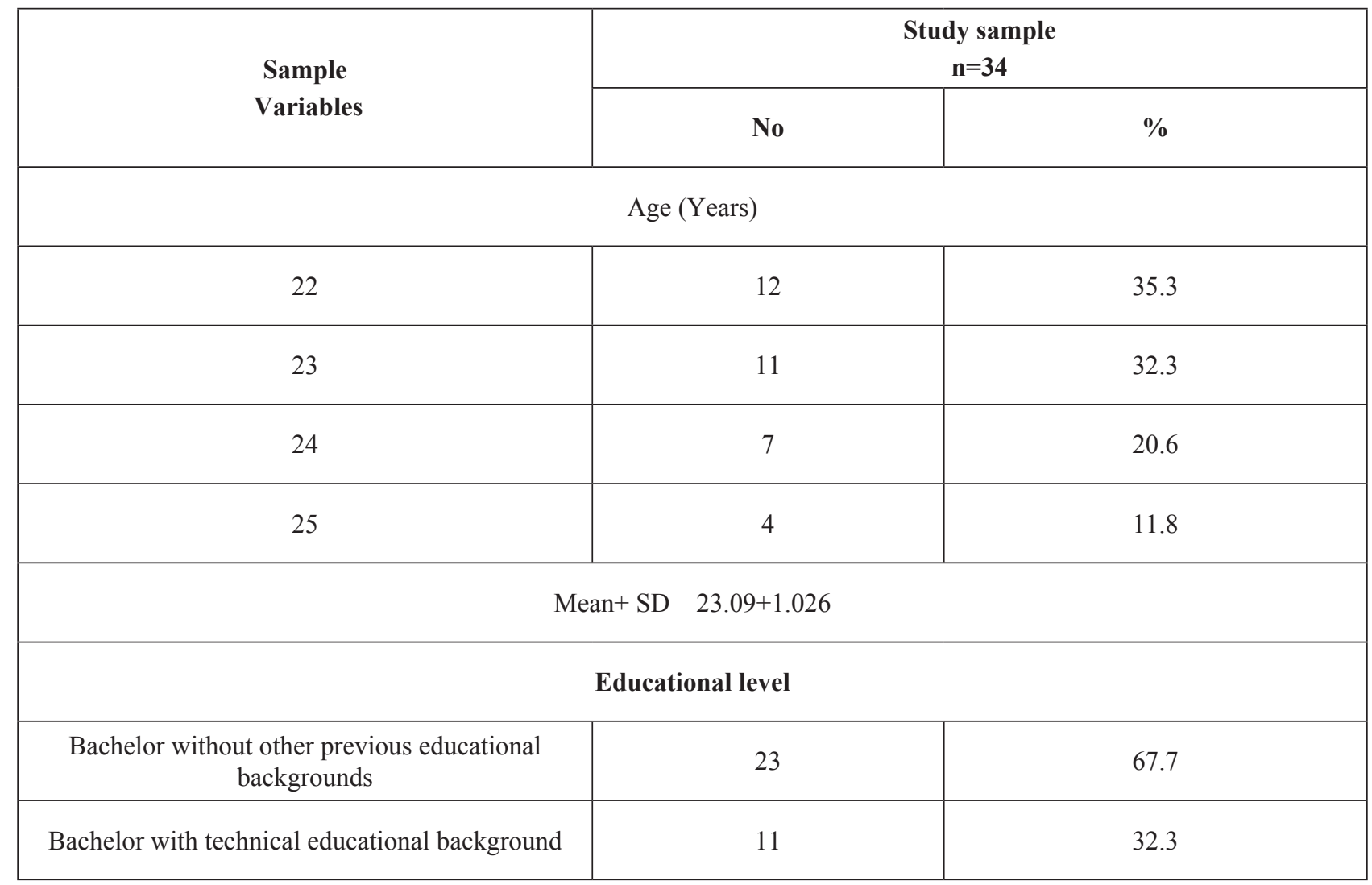




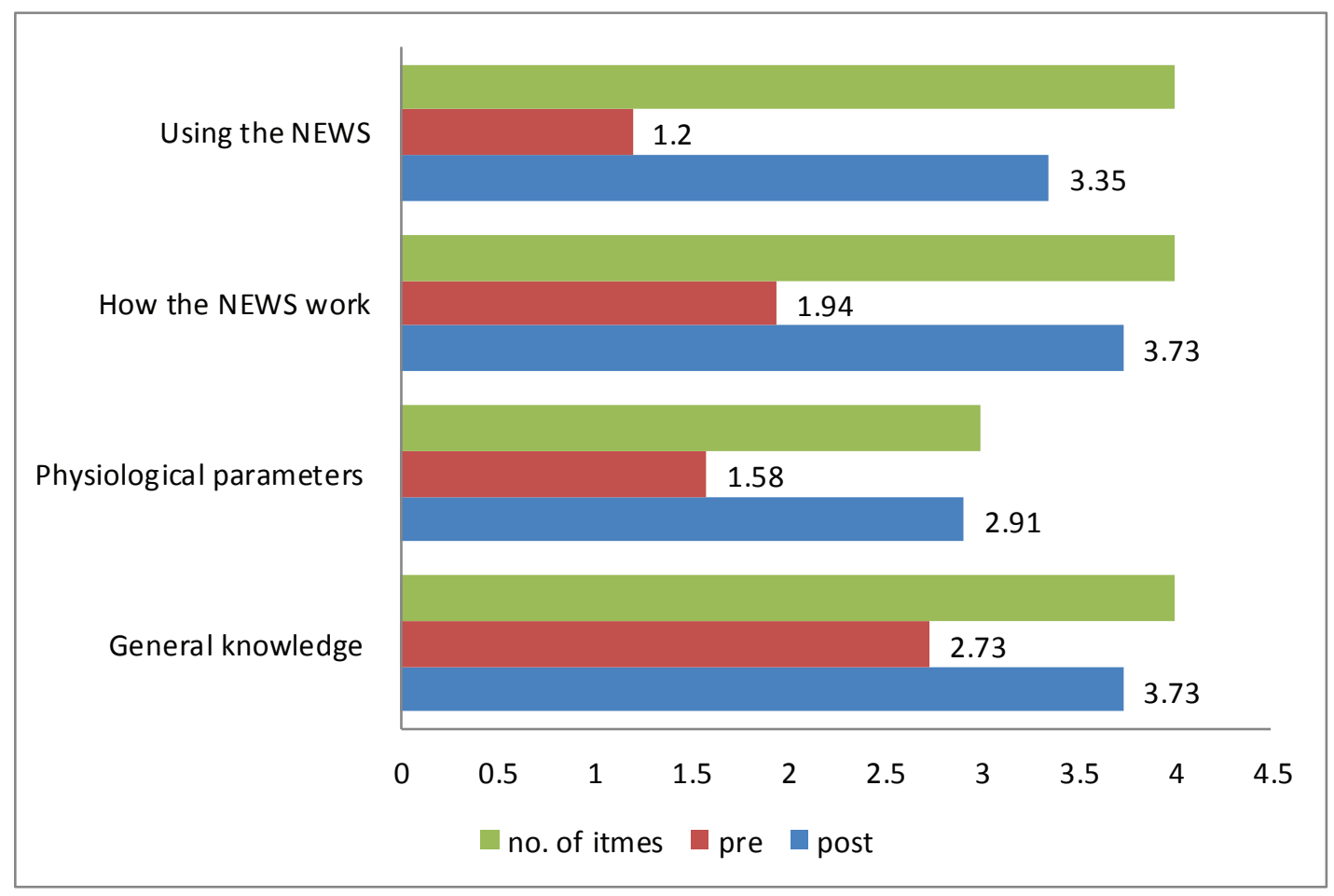

Figure 2: Total and subtotal mean knowledge scores pre \& post educational program of the nurses in relation to NEWS

Table 2: Total and subtotal mean knowledge scores pre \& post educational program of the nurses in relation to NEWS

\begin{tabular}{|c|c|c|c|c|c|}
\hline \multirow{2}{*}{ Items } & \multirow{2}{*}{$\begin{array}{l}\text { Total } \\
\text { score }\end{array}$} & $\begin{array}{c}\text { Pre-educational } \\
\text { program }\end{array}$ & $\begin{array}{c}\text { Post-educational } \\
\text { program }\end{array}$ & \multirow{2}{*}{$\mathbf{t}$} & \multirow{2}{*}{$\mathbf{p}$} \\
\hline & & Mean+ SD & Mean+ SD & & \\
\hline Total knowledge score. & 15 & $7.44+2.286$ & $13.68+1.121$ & -17.77 & $<0.001 *$ \\
\hline General knowledge about NEWS & 4 & $2.7353+.86371$ & $3.7353+.51102$ & -6.330 & $<0.001$ \\
\hline $\begin{array}{c}\text { Physiological parameters incorporated } \\
\text { into the NEWS }\end{array}$ & 3 & $1.5882+.78306$ & $2.9118+.28790$ & -10.616 & $<0.001$ \\
\hline How the NEWS work & 4 & $1.9412+.91920$ & $3.7353+.51102$ & -10.374 & $<0.001$ \\
\hline Using the NEWS & 4 & $1.2059+.84493$ & $3.3529+.59708$ & -14.033 & $<0.001$ \\
\hline
\end{tabular}




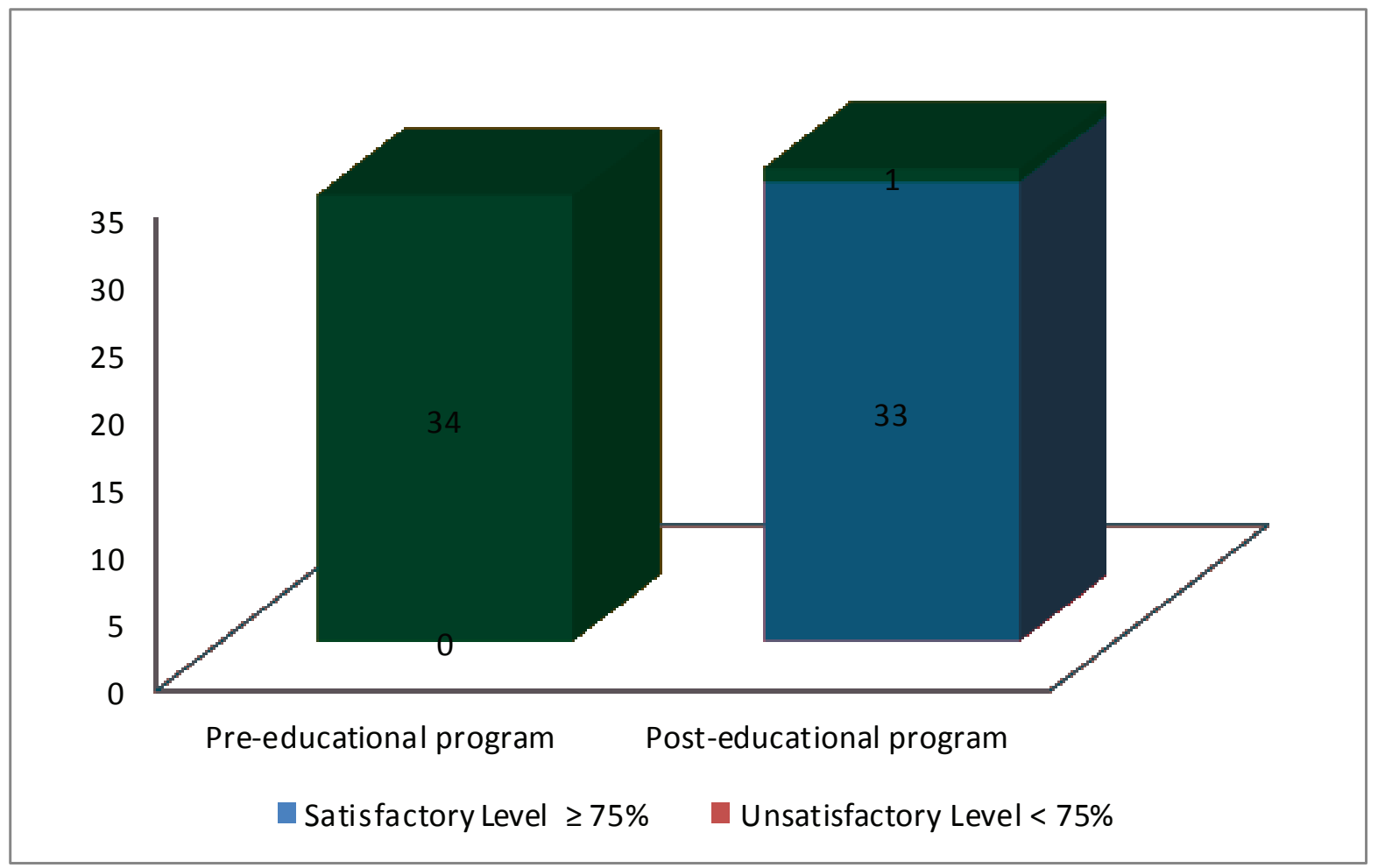

Figure 3: Nurses' knowledge level pre \& post-educational program regarding NEWS

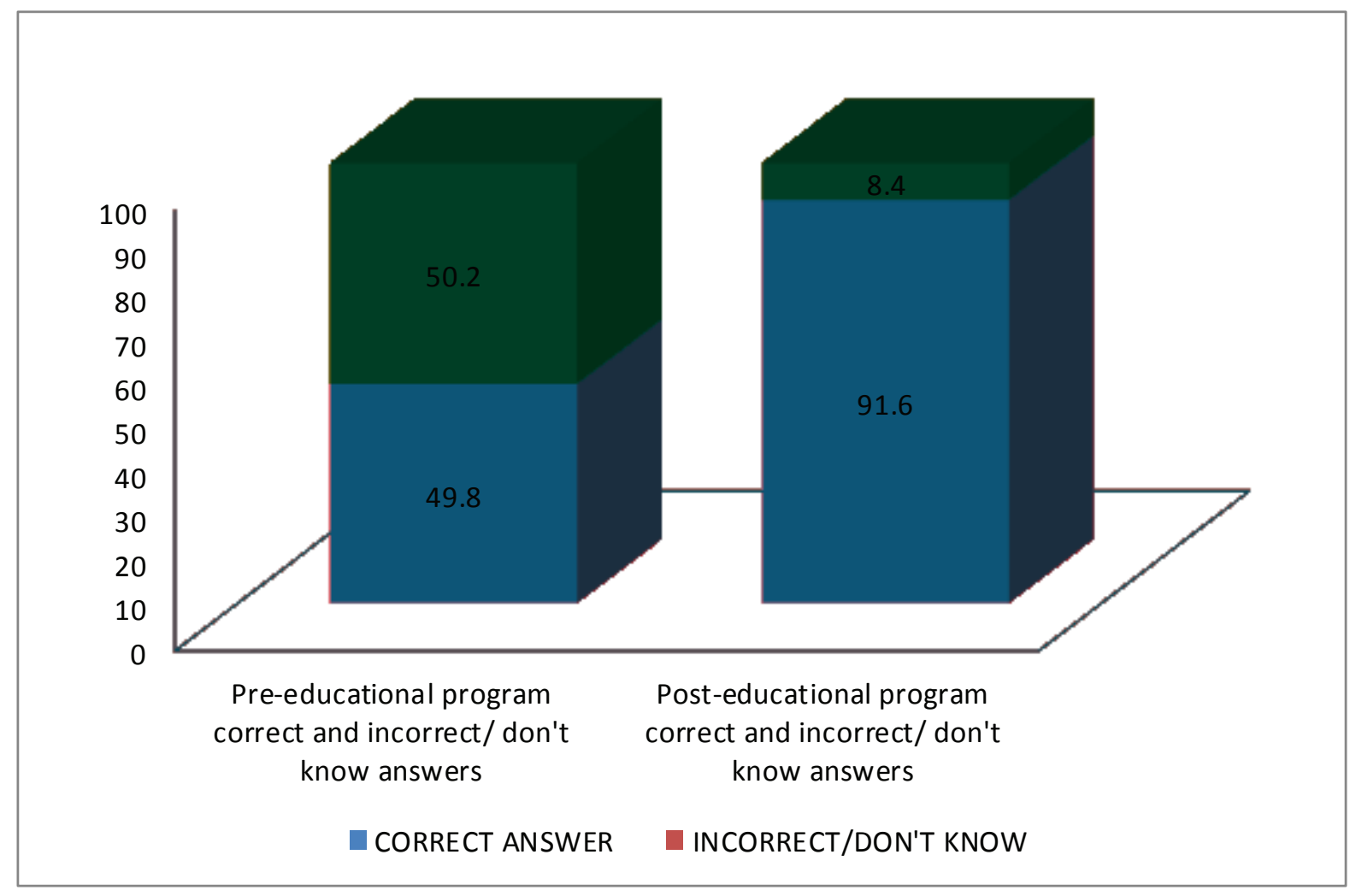

Figure 4: Percentage distribution of correct and incorrect/don't know answers pre \& post educational program regarding NEWS 
Table 3: The relationship between total pre-knowledge and total post knowledge score among the studied nurses' sample in relation to the educational program about NEWS

\begin{tabular}{|c|c|c|c|c|c|}
\hline Items & Mean & Std. Deviation & N & t & p \\
\hline Total pre-knowledge & 7.44 & 2.286 & 34 & $-17.77<0.001^{*}$ \\
\hline Total post-knowledge & 13.68 & 1.121 & 34 & \\
\hline
\end{tabular}

** Correlation is significant at the 0.01 level (2-tailed).

\section{Discussion}

Nurses' demographic data

The current study sample consisted of 34 nurses; about two-thirds of them were females. Concerning age, nearly two-thirds of them were aged (22-23) years. Moreover, all of the nurses included in the educational program have bachelor's degrees, and one-third of them have a technical educational background. This finding is supported by Wiles's study [11], entitled "using the national early warning score as a set of deliberate cues to detect patient deterioration and enhance clinical judgment" the sample was 59 nurses, who were in a medical-surgical, the sample included 46 females (81\%). Their age ranged from 19 to 22 years of age. A similar finding was seen in other studies ${ }^{[12-13]}$

\section{Nurses' knowledge level pre \& post educational} program

Based on NICE's recommendation, all staff caring for patients in acute hospital settings should have competencies in monitoring, interpretation, and timely response to the acutely ill patient. Education and training should be provided to ensure staff has these competencies, and they should be assessed to ensure they can demonstrate them ${ }^{[14]}$. Moreover, the National Clinical Effectiveness Committee ${ }^{[15]}$ recommended that education, training, and demonstrable competency in the use of NEWS should be a mandatory requirement for all healthcare staff engaged in assessing and monitoring acutely ill patients.
In response to the previous recommendation, our educational program in this study aimed to support the dissemination and learning of all nursing staff regarding NEWS and its scoring system by understanding physiological principles of vital signs, reasons for measurement, and derangement. To assess the level of nurse's knowledge regarding national early warning score, the assessment of pre and post-knowledge was implemented.

The present study findings revealed that all nurses had an unsatisfactory knowledge level pre-educational program regarding the early warning scoring system. In contrast, nurses' knowledge level post-educational program showed that most of them (97.1\%) have a satisfactory knowledge level. A possible explanation for increasing nurses' knowledge, the education program empowers the nurses. It enables them to be more aware of the importance of national early warning score in the early detection of acutely ill patients. This finding is matched with a systematic review study done by Saab, et al., ${ }^{[16]}$, who carried out a study entitled "the effect of adult Early Warning Systems education on nurses' knowledge" the result revealed that the EWS educational program succeeded in increasing nurses' knowledge with regard to calculation of EWS and documentation of vital signs, immediately following exposure to the program.

In addition, the finding is consistent with Lindsey \& Jenkins's study ${ }^{[17]}$, which carried out research whereby an early warning education intervention succeeded in enhancing nursing students' understanding of early warning systems. The result revealed that nurses who 
received the education program had significantly higher post-test scores than those who had not received the program. A similar finding was reported by Liaw, et al., ${ }^{[18]}$, and the result revealed that the post-test mean scores of the experimental group were significantly higher than the control group for knowledge after implementing an educational program about rapid response system $(21.29$ vs $18.28, \mathrm{p}<0.001)$. The researcher concludes that educational programs can improve instability recognition and communication, resulting in improved knowledge and decreased time to critical actions.

Further, the current finding is in line with Kyriacos, et al., ${ }^{[19]}$, which introduced a novel MEWS chart and associated training and revealed that nurses' knowledge scores increased from a mean of $4 / 23(19.5 \%)$ at pretest to $14 / 23(61.4 \%)(p=.001) 2$ weeks following the education program. A similar finding was seen in other studies $[12,20]$

The present study findings showed a highly significant statistical difference between total preknowledge and total post-knowledge score among the studied nurses' sample. This finding is supported by Damayanti, Trisyani, \& Nuraeni ${ }^{[21]}$ study. It revealed a significant difference in the pre-test and post-test knowledge within groups, both in the intervention and control groups.

\section{Conclusion}

Education program about NEWS play an essential role in improving nurses' knowledge regarding national early warning score, and no correlation existed between gender, age \& educational level of nurses, and their level of knowledge, while there was a highly significant statistical difference between total pre-knowledge and total post-knowledge.

Recommendation: Provide nurses with educational programs to improve their knowledge regarding the early warning scoring system and replicate the study on a larger sample to obtain generalizable data.

Ethical Clearance: According to the Institutional review board for the protection of human rights, the ethics committee at the faculty of nursing, Cairo University, Egypt, approved the study protocol with reference number IRB 00004025. Also, Informed consent was obtained from all individual participants included in the study.

\section{Source of Funding: Self}

\section{Conflict of Interest: Nil}

\section{References}

1- Massey D, Chaboyer W, Anderson V. What factors influence ward nurses' recognition of and response to patient deterioration? An integrative review of the literature. Nursing open. 2017 Jan;4(1):6-23.

2- Padilla RM, Mayo AM. Clinical deterioration: A concept analysis. Journal of clinical nursing. 2018 Apr;27(7-8):1360-8.

3- Hammond NE, Spooner AJ, Barnett AG, Corley A, Brown P, Fraser JF. The effect of implementing a modified early warning scoring (MEWS) system on the adequacy of vital sign documentation. Australian Critical Care. 2013 Feb 1;26(1):18-22.

4- Connell CJ, Endacott R, Cooper S. The prevalence and management of deteriorating patients in an Australian emergency department. Australasian Emergency Care. 2020 Sep 9.

5- McGaughey J, O’Halloran P, Porter S, Blackwood B. Early warning systems and rapid response to the deteriorating patient in hospital: a systematic realist review. Journal of advanced nursing. 2017 Dec;73(12):2877-91.

6- Royal College of Physicians. National Early Warning Score (NEWS): standardizing the assessment of acute illness severity in the NHS. Report of a working party. RCP; 2012. Retrieved from: https://www.rcplondon.ac.uk Accessed at 12 /3/2021

7- Santos MD, Clifton DA, Tarassenko L. Performance of early warning scoring systems to detect patient deterioration in the Emergency Department. InInternational Symposium on Foundations of Health Informatics Engineering and Systems 2013 Aug 21 (pp. 159-169). Springer, Berlin, Heidelberg.

8- Stevenson JE, Israelsson J, Nilsson GC, Petersson GI, Bath PA. Recording signs of deterioration in acute patients: The documentation of vital 
signs within electronic health records in patients who suffered in-hospital cardiac arrest. Health informatics journal. 2016 Mar;22(1):21-33.

9- Ludikhuize J, Smorenburg SM, de Rooij SE, de Jonge E. Identification of deteriorating patients on general wards; measurement of vital parameters and potential effectiveness of the Modified Early Warning Score. Journal of critical care. 2012 Aug 1;27(4):424-e7.

10- Royal College of Physicians. (2017). National early warning score (NEWS) 2. Standardizing the assessment of acute-illness severity in the NHS. Retrieved from: https://www.rcplondon.ac.uk Accessed at 24/3/2021

11- Wiles BL. Using The National Early Warning Score As A Set Of Deliberate Cues To Detect Patient Deterioration And Enhance Clinical Judgment In Simulation (Doctoral dissertation, Case Western Reserve University) 2016.

12- Leonard MM, Kyriacos U. Student nurses' recognition of early signs of abnormal vital sign recordings. Nurse Education Today. 2015 Sep 1;35(9):e11-8.

13- Liaw SY, Wong LF, Chan SW, Ho JT, Mordiffi SZ, Ang SB, Goh PS, Ang EN. Designing and evaluating an interactive multimedia Web-based simulation for developing nurses' competencies in acute nursing care: randomized controlled trial. Journal of Medical Internet Research. 2015;17(1):e5.

14- National Institute of Clinical Excellence (2007) CG50 Acutely ill patients in hospital. Accessed 25th march 2020 at: http://www.nice.org.uk/ Guidance/CG50/QuickRefGuide/pdf/English
15- National Clinical Effectiveness Committee. National early warning score National Clinical Guideline No. 1 Summary. Access on 24/3/2021 at: https://www.lenus.ie/handle/10147/317078

16- Saab MM, McCarthy B, Andrews T, Savage E, Drummond FJ, Walshe N, Forde M, Breen D, Henn P, Drennan J, Hegarty J. The effect of adult Early Warning Systems education on nurses' knowledge, confidence and clinical performance: A systematic review. Journal of Advanced Nursing. 2017 Nov;73(11):2506-21.

17- Lindsey PL, Jenkins S. Nursing students' clinical judgment regarding rapid response: the influence of a clinical simulation education intervention. InNursing forum 2013 Jan (Vol. 48, No. 1, pp. 6170).

18- Liaw SY, Wong LF, Ang SB, Ho JT, Siau C, Ang EN. Strengthening the afferent limb of rapid response systems: an educational intervention using web-based learning for early recognition and responding to deteriorating patients. BMJ quality \& safety. 2016 Jun 1;25(6):448-56.

19- Kyriacos U, Jelsma J, James M, Jordan S. Early warning scoring systems versus standard observations charts for wards in South Africa: a cluster randomized controlled trial. Trials. 2015 Dec;16(1):1-5.

20- Ozekcin LR, Tuite P, Willner K, Hravnak M. Simulation education: early identification of patient physiologic deterioration by acute care nurses. Clinical Nurse Specialist. 2015 May 1;29(3):16673.

21- Damayanti R, Trisyani Y, Nuraeni A. Effects of Early Warning Score (EWS) Tutorial Simulation on Nurses' Knowledge and Clinical Performance. Nurse Media Journal of Nursing. 2019;9(2):23141. 